MedieKultur | Journal of media and communication research | ISSN 1901-9726

Article - Open issue

\title{
Fake trailers as imaginary paratexts
}

\author{
Mathias Bonde Korsgaard
}

MedieKultur 2020, 68, 107-125

Published by SMID | Society of Media researchers In Denmark | www.smid.dk The online version of this text can be found open access at www.mediekultur.dk

\begin{abstract}
In recent years, trailers have undergone several changes due to the fact that they are now distributed online. The new possibilities in digital production and distribution have also led to the rise of new remix formats that parody and challenge trailer conventions. This article engages with the audiovisual aesthetics of so-called fake trailers in order to deliberate on their paradoxical promotional status. In terms of their audiovisual aesthetics, it is shown how such trailer remixes are driven equally much by the creative (mis)use of sound/music as by rearranging pre-existing shots visually. In terms of their promotional status, it is argued that even though fake trailers have most commonly been seen as proof of an increase in media literacy or as a means for ridiculing trailer conventions, they are nonetheless also firmly entangled in the promotional culture they allegedly aim to denounce. This is exemplified through an examination of the trailer parody "How To Make A Blockbuster Movie Trailer" (2017) made by the remix-duo Auralnauts.
\end{abstract}

\section{Keywords}

Film trailers, fake trailers, media paratexts, audiovisual aesthetics, audiovisual remixing, media literacy 
In recent years, trailers have undergone significant changes due to the fact that they are now mainly distributed online. Consequently, trailers are now available at all times, and they are also no longer only being made for films. While film trailers have only expanded their reach within the world of cinema-with multiple trailers and teasers often being made for the same film - trailers and teasers are now also often made for television series, computer games, music albums, and even for books (see Grøn, 2014), music videos (such as for instance Jonas Åkerlund's teasers for Britney Spears' “Hold It Against Me" in 2011) or certain political events (like for instance the trailer made on the occasion of the meeting between Donald Trump and Kim Jong-un in 2018). Moreover, the new possibilities in digital production and distribution have also led to the rise of a range of new formats that parody and challenge the traditional film trailer, such as, for instance, fake trailers, so-called "Honest Trailers," and other kinds of user-generated trailers that parody ${ }^{1}$ or otherwise ridicule trailer conventions by creating trailers for films that do not exist. Being highly self-reflexive media texts, trailer parodies offer themselves as a relevant starting point for discussing the history and theorization of film trailers in general. Fake trailers are typically made by re-editing footage from actual films into trailers that are deliberately misleading or by creating original trailers for films that simply do not exist. As paratexts to non-existent texts, trailer remixes might be claimed to exhibit a defunct or imaginary paratextuality. Through various kinds of audiovisual manipulation, they criticize trailer and filmmaking conventions. As such, they seemingly distance themselves from any straightforward promotional function. However, this article will argue that they nonetheless often end up circuiting back into having promotional value anyway. The article thus seeks to delineate the audiovisual aesthetics of such trailer remixes, asking specifically how we might understand their paradoxical promotional status as imaginary paratexts.

Near the end of the article, I will examine a YouTube-clip made by the remix duo Auralnauts under the title "How To Make A Blockbuster Movie Trailer" (2017) in detail in order to exemplify the aesthetic and promotional workings of one such concrete trailer parody. This clip has been chosen due to the fact that it poses a parodical poetics of the contemporary mainstream film trailer. On the face of it, it may seem a somewhat singular example, but exploring this particular clip allows for a framing of both the audiovisuality of fake trailers as well as the discussion regarding the promotional nature of such clips. Moreover, this case is not completely one of a kind, seeing that other comparable clips have been made, for instance "Trailer For Every Oscar-Winning Movie Ever" (2010). "How To Make A Blockbuster Movie Trailer" is notable for its particular audiovisual strategy, especially the way in which it uses music, sound and intertitles to conjure up mental images, seeing that this trailer parody in fact contains no actual images, but communicates solely through white words appearing on a black background paired with different sound and music cues. As such, it appears to indirectly confirm one of the main arguments of this article: that the (fake) trailer is generally characterized by an aesthetic 
centrality (or perhaps even primacy) of sound/music (see also Mera, 2009, p. 15; Deaville, 2017; as well as Deaville's research project on "trailaurality" at trailaurality.com).

The second main argument put forth here-namely that fake trailers in fact serve a promotional function whether they intend to or not-may at first seem less obvious when considering this particular case. For one thing, the clip does not use any pre-existing footage from any actual movie and therefore it does not attach itself as an actual paratext to any main text in particular-the "film" being "promoted" simply does not exist. Considering this, it would indeed be an effortless task to simply celebrate the clip, arguing that the media-savvy duo behind Auralnauts are exemplary of the blurring of boundaries between amateur and professional production, that the clip is subversive in its critique of mainstream filmmaking and trailer-making conventions, and that we, as a media literate audience, are in on the joke precisely because we are also sufficiently aware of the conventions being poked fun at-or, in other words, to follow the first two options outlined above concerning media literacy and the critically subversive aspects of media remixing, respectively. I certainly do not mean to claim that this is not also true to some extent. But as the article will hopefully reveal, this clip is also "promotional" and bound up in different kinds of "value production," as is arguably also the case with a great many other kinds of user-generated content situated at any point along the amateur-professional continuum. Fake trailers may seem a somewhat marginal (pseudo)paratextual phenomenon, but discussing them will contribute insights into how even those kinds of paratextuality that are produced outside the industry - and even without direct attachment to any text in particular-cannot avoid but take on promotional functions even if they seemingly have no direct promotional intent. And while fake trailers may seem to be nothing but harmless fun, they exemplify the negotiation over meaning characteristic of much audiovisual remixing. Studying these imaginary paratexts may thus also shed light on promotional culture and value production in a broad sense.

The goal is thus two-fold. Firstly, I insist on the very audiovisuality of these remixes, arguing that it is, in fact, often changes in the soundtrack that are the key aspect of how these remixes work. With reference to Michel Chion, I discuss these trailer remixes in terms of what might be called "the audiovisual Kuleshov effect" (2009, p. 231). This term refers to the way in which sound and image have an instantaneous effect on each other when they are synched-and, in this context, how the simultaneous creative manipulation of sound and image in trailer parodies leads to surprising and often humorous (mis)readings of the imaginary films they "promote." Secondly, I maintain that trailer remixes occupy a paradoxical position in terms of their promotional status. As Daniel Hesford has asked: "If they are adverts, what are they advertising? If they are previews, what are they pre-viewing?" $(2013$, n. p.). This article suggests three possible explanations of the function and purpose of trailer parodies: (1) They can be considered as indications of an "increasing [audiovisual] literacy" (Ortega, 2014, p. 153; see also Hartwig, 2012, p. 224, or Williams, 2016, p. 268); (2) They are meant to criticize conventional trailers and 
mainstream movies (Williams, 2016; Hartwig, 2012, p. 217); or (3) They inevitably end up contributing value to that which they allegedly attempt to criticize.

While the first two perspectives are closely related, the third perspective seems to have been mostly ignored by previous studies of fake trailers. In other words, extant theorizations of this specific media phenomenon tend to downplay the fact that this kind of user-generated content is always-already caught up in commercial and promotional culture, instead opting to point to other rather obvious and predictable frameworks like "participatory culture" (Ortega, 2014, p. 149, in the very first subheading of the article), "textual poaching" (Hesford, 2013, in reference to Jenkins, 1992), or "produsage" (Hartwig, 2012, p. 217, in reference to Bruns, 2008). Such positive perspectives are certainly appealing and surely have some explanatory power, and they generally seem dominant, even though they often only tell half the story. If addressed at all, the critical perspective that many such user activities are not as innocent and value-free as they may seem is only rarely maintained as a persistent framework. To be fair, Ortega is in fact among the few to have briefly touched upon how these kinds of user activities sometimes end up becoming "part of the 'viral marketing equation' of media companies" (2014, p. 150), but this perspective is nonetheless quickly abandoned.

The view presented on fake trailers here is aligned instead with that of Chuck Tryon who, in his take on fake trailers, admits that they "cannot be fully extricated from a wider promotional culture" (2009, p. 155). Even as Tryon's approach to trailer remixes mostly situates them as what he calls "new modes of vernacular textual analysis" (ibid., p. 152)that is, as expressions of a new literacy on behalf of the creators-I share his general insistence to move beyond "models of participatory culture that see it as inherently liberating or that dismiss the ways in which fan practices have become commodified by the entertainment industry" (ibid., p. 9). While participatory online culture may have democratically empowering potentials, opposite aspects of commodification and commercialization also need to be taken equally into account. Still, this does not necessarily mean that $I$ aim to fully denounce the more utopian understandings of such activities. Delivering the keynote at the 2018 NECS conference in Amsterdam, Henry Jenkins compellingly argued for the need for such "utopian thinking," arguing that young people actually often mainly engage with politics through a creative use of popular culture (see also Jenkins, 2019). Of course, it is only positive if media users are generally becoming more audiovisually literate and capable of voicing their opinions, maybe even to the extent of criticizing this or that oppressive mechanism. Moving from critical consumption into critical production is certainly crucial in terms of increasing media literacy. But at the same time, it is equally suspect how such user-driven activities are very often seized by the industry in one way or another-and, therefore, the positivist approaches will always need counterbalancing. There is usually a commercial and promotional underside to user-generated media, even while they may attempt to lure us into believing otherwise. 
The article is structured in three parts. The first part provides historical context related to the history of trailers, but also to the history of the academic study of trailers. The second part discusses the audiovisual foundation of trailer remixes, while the third part analyses Auralnauts' trailer parody. Finally, the article offers some concluding reflections on the functions and purpose of fake trailers.

\section{A history of trailers into the online era}

As trailers have increasingly found themselves at home online, new digital means of production and distribution have also led to the rise of the fake trailers, which are my focus here. Media users now have the tools and materials readily at hand to not only produce, but also to distribute, their own trailers. The fact that trailers for mainstream films now often generate view-counts in the millions and the fact that users sometimes go to the length of creating their own trailers would seem to indicate that trailers are indeed something that many people have come to truly value. However, if we look to the history of trailers, they have not always been equally appreciated. In academia, they have mostly been neglected, probably because of their overtly commercial nature and their alleged aesthetic inferiority. While this is perhaps hardly surprising, it is somewhat surprising that the industry itself originally did not give them much thought either.

Being one of the oldest promotional tools in cinema-with 1912 or 1913 sometimes considered contenders for being the "year zero" of film trailers (Kernan, 2004, p. 25; Fear, 2013) - , it was not until fairly late in the history of cinema that the industry truly realized the promotional potential of the trailer. In an article on early Hollywood film trailers, Keith J. Hamel also notes this lack of industry attention. Referring to the fact that trailers were initially shown after the main feature(s), Hamel suggests that it "is almost as if the name 'trailer,' as something that is designed to draw behind or come last, is an appropriate moniker for a method of advertising that seemed to be an afterthought until of late" (2012, p. 268). Seeing that it was originally the exhibitors and not the producers who made the trailers-and since movies back then were shown in a continuous loop in theaters where the audience could stay for as long as they liked once admission had been paid-, Hamel claims that there was more interest in clearing the theatre seats to make room for new customers than to actually make people want to come back for the coming attractions. Due to this, the trailers were often bad or boring on purpose.

In Lisa Kernan's (2004) historical account, trailer history can be divided into three phases (not counting the silent era): a classical era (from 1927 until the 1950s), a transitional era (until 1975), and a contemporary era (from 1975 onwards). The classical era corresponds roughly to the time when the majority of Hollywood trailers were not created as in-house productions, but created instead by the National Screen Service (NSS). It was not until the 1960s that it became common to make trailers as in-house productions, meaning that this transitional period also witnessed a few experimental trailers, for 
instance the trailers for Hitchcock's Psycho (1960) or Kubrick's Dr. Strangelove (1964). Since 1975, when Jaws birthed the modern-day blockbuster, trailers have become an increasingly important industry tool, and today it is not uncommon for the marketing budget of a movie to almost rival the production budget. Seeing that Kernan's book was published in 2004, this was maybe too early for her to tell that the trailer had probably already entered a fourth phase: the online era. If one were to pinpoint a transitional year, 1999 seems a good bet, with the trailers for films like the first of the second wave of Star Wars movies, The Phantom Menace (1999), which reached a massive audience online (Johnston, 2008, p. 147), and for The Blair Witch Project (1999), which formed part of an original online marketing campaign. The trailers for these two films marked the first time that the film trailer became an online phenomenon. But even before that, the life of trailers had been prolonged beyond their initial run in the movie theatre by having been made available on DVD and VHS, thereby allowing them once again to live up to their name, that is, to possibly trail after movies, and not before them.

In the wake of the online success of trailers, trailers have also received more attention in both film scholarship and journalism. As an example of the latter, the entertainment website The AV Club has published annual lists of "The best movie trailers" every year since 2014. On a somewhat humorous note, they even deemed a mere three seconds of new Game of Thrones-trailer footage newsworthy (Shoemaker, 2018), and trailers for upcoming films and television/streaming series are frequently deemed newsworthy in and of themselves. Likewise, the academic study of trailers has also increased significantly during the 2000s. The two founding texts are Lisa Kernan's aforementioned book from 2004 as well as Keith M. Johnston's book from 2009. Johnston has established himself as a pre-eminent trailer scholar, with a range of articles on trailers in addition to his book. Moreover, some of the recent academic publications that deal with trailers are actually also engaged with trailer remixes. Kathleen Williams has published extensively on the fake trailer format (including a PhD dissertation from 2014), but others have also taken an interest in the phenomenon (see Dusi, 2015; Hesford, 2013; Ortega, 2014; Tryon, 2009).

This increase in scholarly attention may not mean that the trailer has reached the same level of cultural appreciation as another related cinematic paratextual short-form, namely the title sequence (it is difficult to imagine a site devoted to "the art of the trailer" to function as a counterpart to the site Art of the Title [artofthetitle.com]). But the fact that the study of trailers continues to grow also indirectly points to their increased cultural relevance. On a more general level, Jonathan Gray's Show Sold Separately (2010) has become quite the foundational reference in the study of contemporary promotional paratexts, and here, Gray also provides several arguments in support of why such paratexts should be taken seriously. He writes:

For every person who has watched any given film or television program, there are likely more who have watched a trailer, poster, or preview of it and yet not the thing itself. To 
popular culture, then, and hence to media studies' subsequent analyses of what role a text plays in popular culture, the promo and its editor's or producer's meaning-making may prove more important than the meaning-making going on in the show itself. Even in the many instances in which a trailer results in us resolving to never watch the film, clearly some form of interpretation, judgment, and understanding has occurred without the show. (Gray, 2010, p. 52)

While this argument may seem radical and perhaps even deliberately provocative-with the paratext fully outranking the text itself-, it is indeed common for the contemporary media audience to spend significant time engaging with such promotional paratexts, not only by watching them but also by analyzing, debating, and in some cases even producing them. Therefore-in addition to the kinds of "meaning-making" Gray mentions, that of the show/text and the editor/producer-, we should also be attentive to the meaningmaking of the audience itself (see Johnston et al., 2016), here also in the very concretely textual sense that audience members often end up producing additional content themselves, thereby partially short-circuiting the traditional division between producers and recipients of content. To be fair, Gray actually also raises this point later in his book when discussing fan-made title sequences and how such "fan-edits can prefer their own readings" (2010, p. 78). Fake trailers frequently function in a similar way.

One final piece of evidence in support of the argument for the increasing significance of the trailer-albeit a more tangential one-relates to Quentin Tarantino and Robert Rodriguez's Grindhouse project. The two directors joined forces in order to release their respective films Death Proof and Planet Terror as part of the same bill in 2007. This dual film project was accompanied by quite a few fake trailers for imaginary exploitation films created in the same aesthetic vein as the two actual movies of the project. The most interesting one of these-if not aesthetically then at least in terms of its textual function-is the trailer for the film Machete, which was in fact eventually realized as a film by Rodriguez three years later in 2010. Even as this case may be a singular and anomalous example, it is nonetheless a very concrete case of the primacy of the trailer-seeing that the order of production was reversed as the movie was made on the basis of the trailer and not vice versa, as is commonly the case. Many of the comments on the different YouTube-uploads of the trailer for Machete also humorously point to the fact that the initial fake trailer may in fact be better than the movie it eventually gave birth to. These comments frequently raise what has come to be known as a common complaint concerning modern trailers in general, as well as the movies they promote-as exemplified in this comment: "Phenomenal trailer. Movie was a huge disappointment."

Comments such as these speak to the fact that great trailers have certainly been made for bad movies-and mediocre trailers for great films. This is probably due to the fact that the trailer has to walk a tightrope between revealing too little-thereby being boring or inaccurate-or revealing too much-thereby giving the audience all the centerpieces and sometimes even spoiling major plot twists in advance (Deaville, 2017, p. 240; Hediger, 
2001, p. 22; Jensen, 2014, p. 106; Tryon, 2009, p. 157). It has to tell us enough about the movie in order to convince us to watch it while still holding back enough information for the movie itself to remain exciting. A recent study also identifies these points to be among the four typical audience reactions of disappointment in relation to trailers: that the trailer (1) inaccurately misrepresents the film, (2) features all of the "best bits", (3) is better than the film, or (4) reveals too much plot information (Johnston et al., 2016, p. 73). Fake trailers, however, run no such risks - in fact, their humorous effect is dependent on the audience's realization that the trailer is indeed fake and that the film it supposedly supports does not even exist.

\section{The audiovisuality of fake trailers}

The fake trailers for Tarantino and Rodriguez' Grindhouse project are "fake" in another sense than the fake trailers people make themselves, though. The Grindhouse trailers can be considered real trailers for fake movies, whereas what is normally known as fake or spoof trailers can conversely be considered fake trailers for real movies. Kathleen Williams offers a useful distinction between "recut trailers" and "original-footage trailers" (2012, n. p.), with the recut trailers being made up entirely of footage taken from pre-existing films, whereas the original-footage trailers involve actual creation of new content. In terms of the media literacy perspective, it is worth noting that the "recut trailers" came first, perhaps because they require only one set of skills to create: to know how to edit image and sound. The "original-footage trailers" demand a greater effort: to put it in art historian Nicolas Bourriaud's (2002) terms, the "recut trailers" are simply a mode of "postproduction," meaning that they rely fully on reworking existing media materials, whereas the "original-footage trailers" also include an element of actual production.

As mentioned, the recut fake trailers mostly tend to engage in "genre-switching" (Williams, 2016, p. 262), meaning that they take well-known genre films and create fake trailers for them in order to make it appear as if the film belonged to another genre altogether. One of the first examples was made by Robert Ryang in 2005 for Stanley Kubrick's horror classic The Shining from 1980. The significance and exemplary nature of this particular fake trailer is witnessed by the fact that many other scholars have also singled it out (Tryon, 2009, p. 162; Gray, 2010, p. 63; Hartwig, 2012; Hesford, 2013; Ortega, 2014, p. 155; Dusi, 2015, p. 159). Here, the genre of the film in question is also transformed, with the unsettling horror film surprisingly transforming into a family comedy about a struggling writer. This is achieved through a careful selection of shots from the original film, but also equally much through the unexpected addition of Peter Gabriel's "Solsbury Hill" on the soundtrack, a song renowned for its overuse in trailers for romantic comedies (see Greene, 2011). Other early examples of fake trailers that operate along similar lines would include a recut of You've Got Mail (1998), re-envisioned as a suspense thriller with goodguy Tom Hanks turned into a creepy stalker, or one made for Mary Poppins (1964) under 
the title Scary Mary, moving in the opposite direction by making a frightening movie out of a family-friendly one. Most such genre-bending exercises involve taking a light genre and making it dark, or vice versa, and the fake trailers generally seem to play on a deliberate incongruity between the original film and the one the fake trailer turns it into. Other examples include a parodic comedy like Monty Python and the Holy Grail reimagined as a modern-day blockbuster or Steven Spielberg's Jaws becoming a Disney musical with a singing shark.

A great deal of the aesthetic effect of these trailers lies in the meticulous selection of parts from the original movies and the skillful (re-)editing. As such they demonstrate the Kuleshov effect in practice-that is, the discovery made in workshops conducted in the 1910s and 1920s by Soviet silent film director Lev Kuleshov that images may contain meaning in themselves, but that the meaning of any shot can change depending on the shots that precede and follow it. However, something that has not been thoroughly addressed in previous studies of fake trailers is the extent to which the effect of these genre-bending fake trailers also lies in the workings of sound. Like many other kinds of audiovisual remixing, fake trailers demonstrate the reality of Michel Chion's terms of "added value" and "synchresis." To quote one of the ways in which Chion defines his term added value: "Sound shows us the image differently than what the image shows alone" (1994, p. 21). Much of the generic incongruity in the clips is actually created by the addition of music, which assists immensely to a different decoding of the images. In this way, these trailers also show us that genre codes in film rest not only on their visual language, but also very much on their sonic codes-or in the audiovisual interplay between image and sound. By coincidence, Chion in fact also refers to Kuleshov in another passage that resonates clearly with these trailer remixes. Here, he writes that

\footnotetext{
the audiovisual relation is 90 percent a generalized Kuleshov effect, but it is a Kuleshov effect that is "vertical" (through the projection of one element onto another simultaneously) instead of "horizontal" (projection of the meaning or the effect of one element on another that precedes or follows it), such that it is much more immediate and perennially produces an illusion of redundancy (Chion, 2009, p. 231).
}

This is not to say that there is nothing more to the fake trailers than simply substituting the soundtrack, but the sound work is certainly a great part of their allure-the fact that it seems as if all it takes is just a light touch of Peter Gabriel to make us accept a shot of a man kissing a decaying corpse as a romantic interaction in Ryang's fake trailer for The Shining. As suggested by Jason Middleton in relation to the fabled coupling of Pink Floyd's album The Dark Side of the Moon (1973) with the classic American musical The Wizard of Oz (1939) — often called The Dark Side of Oz-, the effectiveness of these types of remix experiments is very much contingent upon "the extent to which the viewer/listener is able to simultaneously perceive two incongruous interpretations of the same scene" (2007, p. 59; see also Richardson, 2012, pp. 190-196). Part of the effect of these remixes thus stems 
from our capability to experience the alternate version of the remix while simultaneously being able to recall the original version - and the mismatch between them.

Others have noted similar things about the related practice of musical mash-ups, which functions in a similar way but in a purely auditory domain. Ragnhild Brøvig-Hanssen and Paul Harkins note how the humorous effect of musical mashups often resides in the fact that they are musically congruent, but contextually incongruent $(2012, \mathrm{p} .87)$. This means that it does in fact sound as if the songs that have been mashed together musically in terms of rhythm, tonality, song structure, etc., but that we are simultaneously well aware of the contextual incongruence between the samples used-which is often of a generic kind, mismatching samples from one musical genre with samples from another both musically and ideologically far-removed genre. In order to fully appreciate this effect, it is necessary for the listener to recognize the samples used, which is why most mashups tend to use well-known hit songs. All these things also apply to our experience of fake trailers and other kinds of audiovisual remixes or mashups. We also mostly recognize the sources involved. We also mostly experience the match between original images and replaced soundtrack as audiovisually congruent, but at the same time, we are also fully aware of the ontological incongruence between original image and replaced soundtrack - we know fully well that even as the audiovisual link may seem perfectly convincing and synched, it is a construct. In fact, this is often why trailer remixes are funny.

Chion's reference to Kuleshov is also interesting in relation to the literacy perspective-because these amateur remixers seem to be intuitively (re-)making some of the same discoveries as the Soviet directors did in their day. Moreover, the media users today make these discoveries in pretty much the same way as the Soviet directors did: by experimenting with found footage (even as the Soviet directors did it due to a shortage of film stock, whereas today it is probably the opposite: it is done due to the sheer overabundance of pre-existing imagery available online). In other words, you could claim that what was once a method preserved for the filmmaking avantgarde has now become something that is potentially available to anyone. It is therefore easy to imagine that making a fake trailer reveals to its creator exactly what the quote above by Chion is saying. In this way, these remixes seem to uncannily reformulate some of the same questions that film theory has asked about sound and its relation to the image from the very start. Another such example comes from an early 1980 text by Claudia Gorbman: "Isn't any music usually sufficient to accompany a segment of film? In fact, the answer is yes. Whatever music is applied to a film segment will do something, will have an effect" (1980, p. 189). Many fake trailers also implicitly ask this question-and provide the exact same answer.

\section{Auralnauts' "How To Make A Blockbuster Movie Trailer"}

Following Williams's distinction between recut and original-footage trailers, the case study I now wish to explore is an original-footage trailer, meaning that it makes no use 
of found sounds or footage. In fact, it does not make use of any actual footage. It was made by a remix duo calling themselves Auralnauts and uploaded under the title "How To Make A Blockbuster Movie Trailer" in 2017. The soundtrack consists of Hans Zimmer-y music and a few lines of invented dialogue. The visuals consist only of white words on a plain black background. These intertitles either describe what we hear-for instance "Low bwaaa followed by ponderous statement or question"-or what we see-for instance "Shots of main characters looking hopeful." Or, to put it more precisely, the intertitles describe the kinds of images we are supposed to see or imagine that we see, or would normally expect to see in a blockbuster trailer. Sometimes, the text even explicates both what we hear and could be seeing-for instance "Big VFX shot with bwaaa."

Since this trailer parody contains no actual imagery, it prompts the question: Is it even an audiovisual text? As viewers, we get no actual images, but only words that sometimes help us conjure some kind of mentally produced images. In another of Michel Chion's terms, this is then perhaps more of an audiologovisual text in that it relies more on sounds and words than on actual images (Chion, 1994, 2012, 2013, 2017). In doing away with filmic images altogether, this parodic trailer also seems to insist that blockbuster trailers are driven by a sonic and/or musical logic, hinting that not only do blockbuster film trailers roughly all follow the same visual tropes, they also often share similar sonic structures.

Of course, it would require a more thorough and perhaps even quantitative analysis of contemporary blockbuster trailers to determine to what degree Auralnauts have figured the blockbuster trailer formula out, but this is not necessarily the point. The point-and thus the joke-is that we are nonetheless convinced that trailers are every bit as formulaic as it is indicated here. The lack of actual images and the fact that they have been reduced to text also seems to imply that due the formulaic nature of blockbuster movies, their images are somewhat interchangeable-as also suggested by the trailer parody itself in the intertitle "Pretty much anything here." This would also lend further support to the argument that trailers are just as much structured on a sonic basis as on a visual one (Deaville, 2017). The clip only needs sound to conjure imagined imagery.

In terms of the soundtrack, much of this trailer parody revolves around what one of the intertitles calls "the unexpected cover of a classic hit." In this case, it is a cover of Dead or Alive's "You Spin Me Round" from 1984. At first listen, it is the lyrics that seem to be the reason behind the choice of this particular song: "You spin me right round, baby, right round // like a record, baby, right round, round, round" (Burns et al., 1984). In the context of this trailer parody, the lyrics seem to reflexively add meaning to what Auralnauts are trying to demonstrate: the "spin round" part refers to the détournement part of their strategy - that is, taking the tropes of the blockbuster trailer and giving them a parodic spin-while the "like a record" part speaks to issues of commodification, massification, standardization, and repetition. But interestingly, the song was also, perhaps by chance, well-chosen if one considers the circumstances of its composition. As it turns out, this song was very directly inspired by a song by the American soul singer Luther Vandross, as 
well as by another song by Nell Campbell, also known as Little Nell, an Australian singer and actress who had her most famous part in the cult movie The Rocky Horror Picture Show from 1975-and signed a record contract only after appearing in this movie.

In a passage from Dead or Alive's lead singer Pete Burns's autobiography, he reveals these circumstances, explaining that he sang another tune over Vandross's "I Wanted Your Love": "that's the way I make music - I hear something and I sing another tune over it" (2007, p. 99). Burns is less specific about the relation to Little Nell's "See You 'Round Like a Record"- though it seems likely that this song inspired the lyrics. In any case, he concludes: "So I had those two, Van Dross [sic] and Little Nell and - bingo! - done deal" (ibid.). In this way, the classic hit that Auralnauts cover was in fact conceived through a compositional method not unlike mashing or remixing - a method that also seems to suggest that just like the individual elements and parts of popular movies are arguably standardized and easily substituted for something similar, the same goes for popular music. In other words, you can always sing another tune over an existing song or replace one chorus with another, just like the imagery in a blockbuster trailer is proposed as being easily interchangeable by the Auralnauts clip.

Many of the arguments made in the theorization of musical mashups thus also seem equally applicable to these kinds of audiovisual remixing. These theorizations often echo Adorno in their critical take on popular music as being founded on standardization, and therefore as something that is "schematic" and "pre-digested" (Adorno, 1941/1999, p. 306). For instance, David J. Gunkel claims that mashups only work because popular songs are "assembled from standard prefabricated components that are repeatable and interchangeable" (2008, p. 494), while Kembrew McLeod claims something similar, noting how they are "made from easily interchangeable, modular components" (2005, p. 86). And if, in the words of Michael Serazio, "the ease of creating a mash-up [...] exposes pop's underlying 'part-interchangeability'” (2008, p. 84), then Auralnauts' parodic trailer equally exposes mainstream cinema's part-interchangeability. In other words, the trailer parody needs no actual imagery because we have seen it all before time and time again.

Pushing this argument to its extreme conclusion, McLeod ponders whether mashups even offer "proof that our culture has withered and run out of ideas" (2005, p. 86). In terms of the fake trailers, it seems clear that this is the logical conclusion to the criticism they put forth, not simply of trailer conventions, but also of mainstream blockbuster film-making conventions in general. After all, if all trailers seem alike, this is only possible because the genre films they advertise rely on standardization and tell stories that we already know in advance. Fake trailers thus often seem to take aim explicitly at the socalled "high concept film" (Wyatt, 1994), that is, films with a crystal-clear premise, sometimes even reducible to a simple tagline or the classic "In a world where..." of many a Don LaFontaine-voiced trailer. Or put in the words of one of the key practitioners of "high concept" filmmaking, Steven Spielberg: "If a person can tell me the idea in twenty-five words or less, it's going to be a good movie" (quoted in Schatz, 1993, p. 33). In a sense, the theo- 
retical inquiries into the high concept films of New Hollywood tie in neatly with Gray's previously mentioned insistence on the partial inversion of the relation between text and paratext. First of all, because the blockbuster is always simultaneously text and commodity, it has become increasingly difficult "to identify or isolate the 'text' itself" (Schatz, 1993, p. 10). But just as importantly, it has often been claimed that the blockbuster itself has mostly lost its status as the main text, having instead become a kind of commercial paratext-meaning that blockbusters are considered "massive advertisements for their product lines" (ibid., p. 33) or as "an advertisement for the games, gadgets, and toys that one can buy after seeing the movie" (Elsaesser, 2001, p. 11; see also King, 2004, p. 29). This is all well and good, and fake trailers are surely not the only participatory remix phenomenon to have humorously echoed this disparaging characterization of contemporary film culture (the brief success of \#ExplainAFilmPlotBadly could be another example of a user-driven phenomenon poking fun at telling "the idea in twenty-five words or less", only again the idea is humorously misrepresented, as when for instance the aforementioned entry in the Star Wars franchise, The Phantom Menace, is deceptively summarized as "Priest kidnaps child for cult and eventual marriage to politician twice his age"). Nonetheless, such criticisms seem somewhat insincere once one considers how fake trailers are not simply disengaged from promotional culture nor disentangled from commercialism.

\section{The function and purpose of trailer remixes}

If the parodic nature of all of these trailer remixes might seem to imply that what was originally a fully promotional format loses its promotional function, then what is the function of such illusory paratexts? As mentioned in the beginning of the article, I suggest three possible angles. I have already touched upon the first one-that remixing trailers is also about learning the workings of audiovisual media, about media literacy and about moving from the role of being a recipient to that of being a producer of content. These trailers arguably exist because of the creators' growing familiarity with the audiovisual language of trailers and of filmmaking in general-, and they are funny to the audience in part because we are familiar enough with audiovisual tropes to recognize when someone subverts these. Like many other kinds of remixing, trailer remixes also occupy a strange sort of middle ground between analysis and production, seeing that their creation is contingent on a close analysis of the source materials in question - searching existing films for repressed meanings and reusable parts. As such, these trailer remixes also end up providing alternate "reading instructions" when compared to those of the original trailers. They point out tiny details, inconsistencies and openings for alternate interpretations, exploiting the fact that the formal structure of any trailer relies "on gaps and associations to be filled with new meaning" (Hartwig, 2012, p. 229)—even if they are often also just plain humorous deconstructions of the film in question. 
Second, these trailers are also typically pointing their fingers at filmmaking clichés. This has been noted by for instance Kathleen Williams, who envisions the fake trailer as "a form through which audiences can mock and subvert" film tropes (2016, p. 261). As noted, it certainly seems to be the highly formulaic nature of trailers - and by extension the formulaic nature of the films they promote-that enables such trailers to be created in the first place (Tryon, 2009, p. 157). But even as fake trailers may hold critical potential, it is also worth noting that they often seem to hold a great deal of affection for the source material; they are also quite often labors of love. And while many trailer remixes seem to formulate a similar critique-aimed at the generic standardization of their source materials-, paradoxically, this is also something that can be leveled against the trailer remixes themselves: once you have seen one of them, you have, in a sense, seen them all. Once you have understood what one of them is trying to say, you also know what the next one will be like.

Therefore, finally, it is a reasonable claim that however hard they try to poke fun at trailer conventions, trailer remixes will always be caught up in promotional culture anyway. Though not related directly to trailers, several critical discussions of "user-generated content" (Andrejevic, 2008; Hesmondhalgh, 2010) lend support to this perspective by partially opposing the more optimist and wide-spread perspectives on participatory culture as empowering the media user (see, for instance, Jenkins, 2006; Bruns, 2008; Lessig, 2008). One of the main objections leveled against these more positivist views on usergenerated content is that the industry often ends up co-opting any user-driven activities, but also that the user-driven activities themselves are not always merely progressive and subversive-and, thus, that "creative activity and exploitation coexist and interpenetrate one another" (Andrejevic, 2008, p. 25). Even if they are critical, fake trailers cannot avoid but end up adding meaning to their source materials. Don't we want to see The Shining again in this new light—or just, simply, see it again in any light—after having seen Robert Ryang's fake trailer? Doesn't a successful fake trailer potentially provide a great deal of positive media coverage for an old film? If considered as textual attempts at criticizing and sabotaging the value chains of promotional culture, fake trailers nevertheless ironically end up forming part of the self-same value chain.

In his passage on this phenomenon, Chuck Tryon also indicates as much, writing:

Even though fake trailers are produced voluntarily by fans who seek no financial compensation for their work, they are also involved in the production of value, whether that value comes from the advertising revenue accumulated by video sharing sites such as YouTube or from the attention directed toward the media texts featured in the parodies. (2009, p. 155; see also Dusi, 2015, pp. 160-161)

In other words, any kind of amateur production will circuit into professional production once it reaches a certain point of popularity - if not necessarily in terms of its quality or the training of the creators or in any other sense of the word, then "professional" in the 
sense that someone makes money out of it, regardless of what the creators' original intention may be.

\section{Conclusion}

Finally, this returns us once again to the Auralnauts example. Seemingly, much of the video consists simply of sound against a black background. Except it is never really just black. Near the beginning, there is a pop-up inviting us to "Click here for the song!" and, at any point whatsoever, there is the Auralnauts channel logo in the lower right corner, reminding us of the creators, allowing or even prompting us to subscribe to their channel. And how does the video end? One possible answer would be, with the humorous final intertitle that says: "Final credit information that appears just long enough to register but is too fast to actually read," which is also an exact description of this intertitle itself, seeing that it disappears before you have had time to read all of it. But the true answer is, with 20 seconds of linked videos and calls for subscribing to Auralnauts' channel. One can of course only conjecture what motivated Auralnauts to make the clip-but in terms of the clip itself, its attempts at critically subverting mainstream cinematic clichés clearly exist side by side with various promotional appeals.

This promotional paradox has been succinctly described by Limor Shifman in her book on memes in digital culture in a passage that briefly discusses fake trailers. To a certain extent, it seems reasonable to claim, on the one hand, that "recut trailers reflect the new power claimed by Internet users" (Shifman, 2014, p. 110). But, on the other hand, Shifman also notes that this does not mean that user-generated trailers are devoid of promotional value: "although these parodied trailers seemingly promote nothing, they actually do promote something: the image of their creators as talented, creative, and digitally literate people" (ibid.). Fake trailers are thus suspended between the three different perspectives suggested in this article (literacy, critique, promotion), but scholars have tended to focus mostly on the aspects of media literacy and critical subversion and less on the inherent promotional aspect.

In his recent chapter on transmedia paratexts, Matt Hills concludes that paratexts "are no longer merely powerful tools of branding or textual (pre-)interpretation; instead they have been repositioned as a new terrain for audience struggles over [...] meaning-making" (2019, p. 294). Such arguments appear to readily line up with fake trailers as a relatively new type of paratext: through audiovisual manipulation, they offer a critical interrogation of the meaning-making taking place in mainstream cinema. The question remains, though, how deep does this criticism run? Considering how fake trailers also simultaneously carry out promotional functions, it seems quite a stretch to claim, for instance, that they fully undermine "the hierarchical structures of the traditional media industry" (Hartwig, 2012, p. 216). As this article hopefully shows, such celebratory arguments are partly misleading-because, in the words of Elizabeth Bird, celebrating the online pro- 
ducer runs the risk of masking "the ever-increasing power of the media industry" (2011, p. 507). It thus seems more reasonable to situate phenomena like fake trailers as exhibiting both an affection for and a denunciation of mainstream cinema. Fake trailers remind us that telling and selling are two sides of the same coin, and that the contemporary paratext is naturally suspended between textual and commercial logics. Fake trailers certainly offer a quick knowing laugh, but they also remind us how efficiently genre films and film trailers normally communicate-and the Hollywood machinery probably could not care less about fake trailers. In a certain sense, the way in which Auralnauts are able to build paratextual hype for a film that never existed in the first place therefore also becomes a testament to the effectiveness of the highly standardized format that is the film trailer, in that it manages to build hype for a film that will never be.

\section{Notes}

1 In Linda Hutcheon's famous definition, parody involves "repetition with difference" and with a "critical distance" (1985, pp. 32). Trailer parodies frequently recombine footage from existing films in new ways, and even when they do not incorporate existing footage, they still rely on repetition in their misappropriation of genre codes.

2 Comment by YouTube-user Darren Cole on this upload of the trailer: https://www.youtube.com/ watch?v=zzoeBdEjOFI (accessed July 2, 2020).

\section{References}

Adorno, T. (1990). On popular music. In S. Frith, \& A. Goodwin (Eds.), On Record: Rock, pop, and the written word (pp. 256-267). New York: Routledge, 1990. (Original work published 1941).

Andrejevic, M. (2008). Watching television without pity: The productivity of online fans. Television \& New Media, 9(1), 24-46. Retrieved July 2, 2020, from https://doi.org/10.1177/1527476407307241.

Bird, S.E. (2011). Are We All Produsers Now? Cultural Studies, 25(4-5), 502-516. Retrieved July 2, 2020, from http://doi.org/10.1080/09502386.2011.600532.

Bourriaud, N. (2002). Postproduction. New York: Lucas \& Sternberg.

Bruns, A. (2008). Blogs, Wikipedia, Second Life, and Beyond: From production to produsage. New York: Peter Lang.

Brøvig-Hanssen, R., \& Harkins, P. (2012). Contextual incongruity and musical congruity: The aesthetics and humour of mash-ups. Popular Music, 31(1), 87-104. Retrieved July 2, 2020, from https://doi.org/10.1017/ S026114301100047X.

Burns, P. (2007). Freak Unique: My autobiography. London: John Blake Publishing.

Chion, M. (1994). Audio-Vision: Sound on screen (C. Gorbman, Trans.). New York: Columbia University Press.

Chion, M. (2009). Film: A sound art (C. Gorbman, \& C. J. Deloglu, Trans.). New York: Columbia University Press.

Chion, M. (2012). 100 concepts pour penser et décrire le cinéma sonore. (Accessible as a free download if you provide an email address via http://michelchion.com/texts. Also features a translation by Claudia Gorbman under the title 100 Concepts to Think and Describe Sound Cinema.)

Chion, M. (2013). The audio-logo-visual and the sound of languages in recent film. In J. Richardson, C. Gorbman, \& C. Vernallis (Eds.), The Oxford Handbook of New Audiovisual Aesthetics (pp. 
77-88). Oxford: Oxford University Press. Retrieved July 2, 2020, from https://doi.org/10.1093/oxfor dhb/9780199733866.013.0029.

Chion, M. (2017). Sound: An acoulogical treatise (J.A. Steintrager, Trans.). Durham, North Carolina: Duke University Press.

Deaville, J. (2017). Trailer or leader? The role of music and sound in cinematic previews. In M. Mera, R. Sadoff, \& B. Winters (Eds.), The Routledge Companion to Screen Music and Sound (pp. 240-254). New York: Routledge. Retrieved July 2, 2020, from https://doi.org/10.4324/9781315681047-20.

Dusi, N.M. (2015). Remixing movies and trailers before and after the digital age. In E. Navas, O. Gallagher, \& x. burrough (Eds.), The Routledge Companion to Remix Studies (pp. 154-165). New York: Routledge.

Elsaesser, T. (2001). The blockbuster: Everything connects, but not everything goes. In J. Lewis (Ed.), The End of Cinema as We Know It: American film in the nineties (pp. 11-22). New York: NYU Press.

Fear, D. (2013, October 28). Becoming attractions: A brief history of film trailers. The Dissolve. Retrieved July 2, 2020, from http://thedissolve.com/features/exposition/241-becoming-attractions-a-brief-history-offilm-trail/.

Gorbman, C. (1980). Narrative film music. Yale French Studies, (60), 183-203. Retrieved July 2, 2020, from https://doi.org/10.2307/2930011.

Gray, J. (2010). Show Sold Separately: Promos, spoilers, and other media paratexts. New York: NYU Press.

Greene, A. (2011, October 10). Peter Gabriel: Story that Bruce Springsteen was inspiration for 'Solsbury Hill' is 'hogwash'. Rolling Stone. Retrieved July 2, 2020, from https://www.rollingstone.com/music/musicnews/peter-gabriel-story-that-bruce-springsteen-was-inspiration-for-solsbury-hill-is-hogwash-72349/.

Grøn, R. (2014). Literary experience and the book trailer as intermedial paratext. SoundEffects, 4(1), 90-107. Retrieved July 2, 2020, from https://doi.org/10.7146/se.v4i1.20330.

Gunkel, D.J. (2008). Rethinking the digital remix: Mash-ups and the metaphysics of sound recording. Popular Music and Society, 31(4), 489-510. Retrieved July 2, 2020, from https://doi. org/10.1080/03007760802053211.

Hamel, K.J. (2012). From advertisement to entertainment: Early Hollywood film trailers. Quarterly Review of Film and Video, 29(3), 268-278. Retrieved July 2, 2020, from https://doi. org/10.1080/10509201003667218.

Hartwig, L. (2012). You'll never see this on the silver screen: The film trailer as a template for the appropriation and transformation of Hollywood movies. In K. Loock, \& C. Verevis (Eds.), Film Remakes, Adaptations and Fan Productions (pp. 215-230). Basingstoke: Palgrave Macmillan. Retrieved July 2, 2020, from https://doi.org/10.1057/9781137263353.0019.

Hediger, V. (2001). Verführung zum Film. Der amerikanische Kinotrailer seit 1912. Marburg: Schüren.

Hesford, D. (2013). Action... suspense... emotion! The trailer as cinematic performance. Frames Cinema Journal, (3), unpaginated. Retrieved July 2, 2020, from http://framescinemajournal.com/article/actionsuspense-emotion-the-trailer-as-cinematic-performance/.

Hesmondhalgh, D. (2010). User-generated content, free labour and the cultural industries. Ephemera:

Theory \& Politics in Organization, 10(3/4), 267-284. Retrieved July 2, 2020, from http://www.ephemerajournal.org/contribution/user-generated-content-free-labour-and-cultural-industries.

Hills, M. (2019). Transmedia paratexts: Informational, commercial, diegetic, and auratic circulatin. In M.

Freeman, \& R. Rampazza Gambarato (Eds.), The Routledge Companion to Transmedia Studies (pp. 289296). New York: Routledge. Retrieved July 2, 2020, from https://doi.org/10.4324/9781351054904-32.

Hutcheon, L. (1985). A Theory of Parody: The teachings of twentieth-century art forms. New York: Methuen. Jenkins, H. (1992). Textual Poachers: Television fans and participatory culture. New York: Routledge. Jenkins, H. (2006). Convergence Culture: Where old and new media collide. Cambridge, Massachusetts: MIT Press. 
Jenkins, H. (2018, June 27). Popular culture as politics, politics as popular culture. Keynote at the NECS Conference, Amsterdam, the Netherlands.

Jenkins, H. (2019). Popular culture as politics, politics as popular culture. The Journal of Media Literacy. Retrieved July 2, 2020, from https://www.journalofmedialiteracy.org/jenkins-article-2019.

Jensen, C.S. (2014). Reduced narration, intensified emotion: The film trailer. Projections, 8(1), 105-125. Retrieved July 2, 2020, from https://doi.org/10.3167/proj.2014.080107.

Johnston, K. (2008). The coolest way to watch movie trailers: Trailers in the digital age. Convergence: The International Journal of Research into New Media Technologies, 14(2), 145-160. Retrieved July 2, 2020, from https://doi.org/10.1177\%2F1354856507087946.

Johnston, K. (2009). Coming Soon: Film trailers and the selling of Hollywood technology. London: McFarland and Co.

Johnston, K., Vollans, E., \& Greene, F. (2016). Watching the trailer: Researching the film trailer audience. Participations: Journal of Audience \& Reception Studies, 13(2), 56-85. Retrieved July 2, 2020, from https://www.participations.org/Volume\%2013/lssue\%202/5.pdf.

Kernan, L. (2004). Coming Attractions: Reading American movie trailers. Austin: University of Texas Press.

King, N. (2004). The last good time we ever had. In T. Elsaesser, A. Horwath, \& N. King (Eds.), The Last Great American Picture Show (pp. 19-36). Amsterdam: Amsterdam University Press. Retrieved July 2, 2020, from https://doi.org/10.1515/9789048503681-002.

Lessig, L. (2008). Remix: Making art and commerce thrive in the hybrid economy. London: Bloomsbury.

McLeod, K. (2005). Confessions of an intellectual (property): Danger Mouse, Mickey Mouse, Sonny Bono, and my long and winding path as a copyright activist-academic. Popular Music and Society, 28(1), 79-93. Retrieved July 2, 2020, from https://doi.org/10.1080/0300776042000300981.

Mera, M. (2009). Invention/re-invention. Music, Sound, and the Moving Image, 3(1), 1-20. Retrieved July 2, 2020, from https://doi.org/10.3828/msmi.3.1.1.

Middleton, J. (2007). The audio-vision of found footage film and video. In R. Beebe, \& J. Middleton (Eds.), Medium Cool: Music videos from soundies to cellphones (pp. 59-82). Durham, North Carolina: Duke University Press. Retrieved July 2, 2020, from https://doi.org/10.1215/9780822390206-004.

Ortega, V.R. (2014). Spoof trailers, hyperlinked spectators \& the web. New Media \& Society, 16(1), 149-164. Retrieved July 2, 2020, from https://doi.org/10.1177\%2F1461444813479000.

Richardson, J. (2012). An Eye for Music: Popular music and the audiovisual surreal. Oxford: Oxford University Press.

Schatz, T. (1993). The new Hollywood. In J. Collins, H. Radner, \& A.P. Collins (Eds.), Film Theory Goes to the Movies (pp. 8-36). New York: Routledge.

Serazio, M. (2008). The apolitical irony of generation mash-up: A cultural case study in popular music. Popular Music and Society, 31(1), 79-94. Retrieved July 2, 2020, from https://doi. org/10.1080/03007760701214815.

Shifman, L. (2014). Memes in Digital Culture. Cambridge, Massachusetts: MIT Press.

Shoemaker, A. (2018, August 27). Oh shit, there's 3 seconds of new Game of Thrones footage. The AV Club. Retrieved July 2, 2020, from https://news.avclub.com/oh-shit-there-s-three-seconds-of-new-game-ofthrones-fo-1828626205.

Tryon, C. (2009). Reinventing Cinema: Movies in the age of media convergence. London: Rutgers University Press.

Williams, K.A. (2012). Fake and fan film trailers as incarnations of audience anticipation and desire. Transformative Works and Cultures, 9, unpaginated. Retrieved July 2, 2020, from https://doi.org/10.3983/ twc.2012.0360. 
Williams, K.A. (2014). The Recut Trailer as Networked Object: Anticipation and nostalgia in the YouTube era. [PhD dissertation, School of the Arts and Media, UNSW, Australia].

Williams, K.A. (2016). Extended attractions: Recut trailers, film promotion, and audience desire. In A.A. Klein, \& R.B. Palmer (Eds.), Cycles, Sequels, Spin-Offs, Remakes, and Reboots: Multiplicities in film and television (pp. 260-276). Austin: University of Texas Press.

Wyatt, J. (1994). High Concept: Movies and marketing in Hollywood. Austin: University of Texas Press.

\section{YouTube clips}

"Britney Spears - 'Hold It Against Me' Teaser \#1" (2011). Uploaded by Britney Spears on February 4, 2011. https://www.youtube.com/watch?v=leRIViWiynU.

"How To Make A Blockbuster Movie Trailer" (2017). Uploaded by Auralnauts on August 14, 2017. https:// www.youtube.com/watch?v=KAOdjqyG37A.

"Machete Trailer [HQ]" (2010). Uploaded by cristoph258 on June 30, 2010. https://www.youtube.com/ watch?v=zzoeBdEjOFI.

"Monty Python and the Holy Grail Modern Trailer" (2013). Uploaded by Stéphane Bouley on September 10, 2013. https://www.youtube.com/watch?v=hKNDml12Big.

"Shining HQ" (2012). HQ remake of Robert Ryang's original The Shining fake trailer. Uploaded by TheLateGrahamChapman on September 8, 2012. https://www.youtube.com/watch?v=6s40Q6ODSI8.

"The action-movie style trailer Trump says he played to Kim Jong-un" (2018). Uploaded by Guardian News on June 12, 2018. https://www.youtube.com/watch?v=aYsaC2CADs0.

“The Dark Side of Oz" (2013). Uploaded by Rolf Renton on March 21, 2013. https://www.youtube.com/ watch?v=NtExVJlgECO.

“THE ORIGINAL Scary 'Mary Poppins' Recut Trailer” (2006). Uploaded by moviemker on October 9, 2006. https://www.youtube.com/watch?v=2T5_0AGdFic.

“Trailer For Every Oscar-Winning Movie Ever" (2010). Uploaded by Cracked on March 6, 2010. https:// www.youtube.com/watch? $v=$ rbhrz1-4hN4.

"What If 'Jaws' Was A Disney Movie?" (2011). Uploaded by Italianoboy UK on December 8, 2011. https:// www.youtube.com/watch?v=Dr1pFnjj6H0.

"You've Got Mail Recut" (2006). Uploaded by jdfilms on December 15, 2006. https://www.youtube.com/ watch? $v=2$ debV8fkLhc.

\section{Songs}

Burns, P., Coy, S., Hussey, W., Lever, T. \& Lever, M. (as Dead or Alive), "You Spin Me Round (Like a Record)”. On You Spin Me Round (Like a Record) [single]. Los Angeles: Epic Records.

This work was supported by the Independent Research Fund Denmark under Grant number DFF-4089-00149 ('Audiovisual Literacy and New Audiovisual Short-Forms').

Mathias Bonde Korsgaard Assistant Professor Department of Media and Journalism Studies Aarhus University mbk@cc.au.dk 